\title{
Synthesis, Characterization and Conformational Analysis of Two Novel 4(1H)-Quinolinones
}

\author{
Lidiane J. Michelini, ${ }^{\oplus a, b}$ Wesley F. Vaz, ${ }^{c}$ Luiz F. N. Naves, ${ }^{c}$ Caridad N. Pérez ${ }^{a}$ and \\ Hamilton B. Napolitano ${ }^{\circledR} *, c, d$ \\ anstituto de Química, Universidade Federal de Goiás, 74690-900 Goiânia-GO, Brazil \\ ${ }^{b}$ Instituto Federal de Ciência, Educação e Tecnologia Goiano, 76200-000 Iporá-GO, Brazil \\ ${ }^{c}$ Ciências Exatas e Tecnológicas, Universidade Estadual de Goiás, 75132-903 Anápolis-GO, Brazil \\ ${ }^{d}$ Laboratório de Novos Materiais, Centro Universitário de Anápolis, \\ 75083-515 Anápolis-GO, Brazil
}

\begin{abstract}
Quinolinones are a class of organic compounds known as alkaloids found in several plants and also can be synthesized. Their large use in therapies regards their wide biological potential like antitumor, psychiatric and neurological agents. Two substances were structurally characterized: (E)-3-(2-nitrobenzylidene)-2-(4-methoxyphenyl)-1-(phenylsulfonyl)-2,3-dihydroquinolin4(1H)-one (NMQ), and (E)-3-(2-chlorobenzylidene)-2-(2-methoxyphenyl)-1-(phenylsulfonyl)2,3-dihydroquinolin-4(1H)-one (CMQ). These compounds were synthesized, crystallized, characterized by single crystal X-ray diffraction and theoretical calculations. The NMQ and CMQ crystals are formed by a pair of enantiomers and crystallized in the centrosymmetric group P21/c with similar volume and density. Differences noted on crystal packing and supramolecular arrangement are associated to substituent group chlorine in CMQ and nitro in NMQ. The calculated infrared (IR) spectra show a good agreement with experimental values. The highest occupied molecular orbital (HOMO) and lowest unoccupied molecular orbital (LUMO) energies show CMQ more kinetically stable with a higher resistance to transfer charge than NMQ.
\end{abstract}

Keywords: quinolinones, X-ray diffraction, theoretical analysis

\section{Introduction}

Organic compounds known as quinolinones alkaloids are found in several plants and have been used as remedies since ancient times. ${ }^{1}$ The $4(1 H)$-quinolinones are a class of these compounds that occurs naturally in the environment and also can be synthesized. ${ }^{2,3}$ Their application is largely known as antibiotic in the treatment of infection, ${ }^{4}$ but other studies have shown that these compounds may be used in many areas, for example, in medicine with different biological potential uses, ${ }^{5-11}$ like antitumor ${ }^{12,13}$ or psychiatric and neurological agents ${ }^{14}$ or in engineering by their photophysical properties. ${ }^{15}$ For a better understanding of where and how these substances may be used, the structural investigation is a significant tool. It provides a complete knowledge of the molecular structure embracing the atomic architecture, molecular conformation and crystal packing.

*e-mail: hbnapolitano@gmail.com
Owing this information, it is possible to open new frontiers, including the development of novel materials and drugs. ${ }^{16}$ This sort of analysis is largely applied for the acquaintance of quinolinones providing, for example, information about the relationship between structure and activity in biological tests. ${ }^{17,18}$

With the aim to obtain structural information of novel $4(1 H)$-quinolinones, two substances were analyzed: (E)-3-(2-nitrobenzylidene)-2-(4-methoxyphenyl)1-(phenylsulfonyl)-2,3-dihydroquinolin-4(1H)-one (NMQ), and (E)-3-(2-chlorobenzylidene)-2-(2-methoxyphenyl)1-(phenylsulfonyl)-2,3-dihydroquinolin-4(1H)-one (CMQ). Thus, the purpose is the structural elucidation throughout the single crystal X-ray diffraction methodology, encompassing crystalline arrangement, interatomic distance and angles, molecular geometry, inter and supramolecular interactions and Hirshfeld surface analysis. In this aspect, this work provides important information for future studies and applications of the 4-(1H)-quinolinones. 


\section{Experimental}

\section{Synthesis and crystallization}

NMQ (5) and CMQ (6) were obtained from sulfonamide chalcones $\mathbf{1}$ and $\mathbf{2}$, and reacted with benzaldehydes $\mathbf{3}$ and 4 (2:1), respectively (Scheme 1), in alkaline reaction environmental for $24 \mathrm{~h}$. The resulting precipitates 5 and 6 were purified by multi-solvent slow recrystallization from dichloromethane $\left(\mathrm{CH}_{2} \mathrm{Cl}_{2}\right)$ and ethanol $\left(\mathrm{CH}_{3} \mathrm{CH}_{2} \mathrm{OH}\right)(4: 1)$, after drying at room temperature.

\section{Crystallographic characterization}

A radiation of graphite monochromated MoK $\alpha$ with a wavelength of $0.71073 \AA$, at room temperature, was focused in a single crystal of NMQ and CMQ using a Bruker Apex II CCD diffractometer. This was executed to collect the diffraction data. Right after, this data were processed utilizing the Bruker program APEX2, ${ }^{19}$ choosing the direct methods as the option for the structure solution. The software SHELX $2016^{20}$ was employed for the refinement, opting for the least square methods. For the positioning and calculation of the hydrogen atoms, the refinement was fixed with individual displacement parameter [Uiso $(\mathrm{H})=1.2$ Ueq or $1.5 \mathrm{Ueq}]$, using $0.97 \AA$ as the lengths of $\mathrm{C}-\mathrm{H}$ for aromatic groups, and $0.97 \AA$ for methyl groups. Structural information described in tables, figures and molecular representations were made using the softwares WinGX, ${ }^{21}$ Ortep $^{21}$ and Mercury, ${ }^{22}$ respectively. The PLATON ${ }^{23}$ program was also utilized to verify the possible interactions involving hydrogen bonds.

\section{Hirshfeld surface analysis}

To measure the intermolecular interactions in the crystal arrangement of NMQ and CMQ, Crystal Explorer 3.1 software $^{24,25}$ was selected as a tool of Hirshfeld surface (HS) analysis. Due to this, the graphical representation of the normalized contact distances $\left(\mathrm{d}_{\text {norm }}\right)$, shape index and
2D fingerprint plot of both compounds was possible. To represent the HS, it was used a diagram that illustrated the molecular interactions with different grades, which change according to the atoms and connections types on the surface of the molecule. ${ }^{26}$ It allows a visualization and a better understanding about which interaction is more and less significant for the crystal packing. ${ }^{27}$ The base to generate an HS is to branch the space in regions according to electronic distribution engendering the weighting function $\mathrm{W}(\mathrm{r})$, which corresponds to the value of 0.5 . In this equation, ${ }^{25}$ the sum of the electronic contribution of part of the molecule overlaps the contribution of all the crystal, represented by:

$\mathrm{W}(\mathrm{r})=\frac{\rho_{\text {molecule }}(\mathrm{r})}{\rho_{\text {crystal }}(\mathrm{r})}$

Meanwhile, when near contacts are present, it is possible to analyze using the distance function. It enables the formation of two regions in the intermolecular contact characterized by donation and acceptance properties and can be equated $\mathrm{d}_{\text {norm }} \cdot{ }^{28}$

$d_{\text {norm }}=\frac{\left(d_{i}-r_{i}^{v d W}\right)}{r_{i}^{v d W}}+\frac{\left(d_{e}-r_{e}^{v d W}\right)}{r_{e}^{v d W}}$

The two regions compose the surface taking intern and extern atomic nucleus as references. The accept region $\left(\mathrm{d}_{\mathrm{i}}\right)$ is the distance from an internal atom to HS, while the $d_{e}$ region is equivalent to the donor region measuring from an external atomic nucleus until HS. ${ }^{28}$ These two distances combined in a 2D graph, called fingerprint, give unique information about the contacts present in the structure. ${ }^{25}$ Another useful appliance provided by HS is the recognition of hydrophobic interactions by means of shape index $(\mathrm{S})$ analysis, which is a dimensionless qualitative measure of surface shape, defined in terms of principal curvatures $\kappa_{1}$ and $\kappa_{2}$ by the function:

$\mathrm{S}=\frac{2}{\pi} \arctan \frac{\kappa_{1}+\kappa_{2}}{\kappa_{1}-\kappa_{2}}$
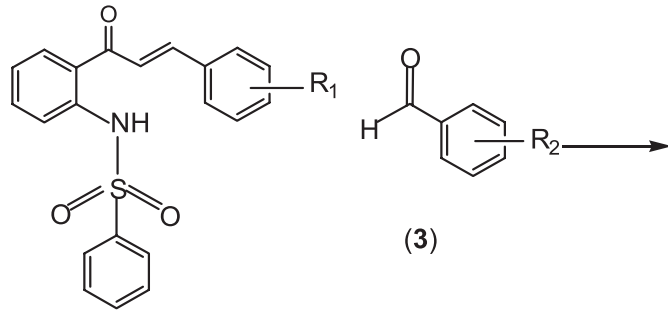

(3)
(1): $\mathrm{R}_{1}=p-\mathrm{CH}_{3}$
(2): $\mathrm{R}_{1}=\mathrm{O}-\mathrm{OCH}_{3}$
(3): $\mathrm{R}_{2}=0-\mathrm{Cl}$
(4): $\mathrm{R}_{2}=\mathrm{o}-\mathrm{NO}_{2}$



(5): $\mathrm{R}_{1}=p-\mathrm{CH}_{3} ; \mathrm{R}_{2}=o-\mathrm{NO}_{2}$ (6): $\mathrm{R}_{1}=\mathrm{o}-\mathrm{OCH}_{3} ; \mathrm{R}_{2}=\mathrm{Cl}$

Scheme 1. Synthesis of NMQ (5) and CMQ (6). 


\section{Computational details}

Theoretical calculations, at density functional theory (DFT) methods, were done with Gaussian 09 package $^{29}$ to obtain the optimized geometry, vibrational wavenumbers and theoretical vibrational spectra of CMQ and NMQ. In the literature, M06-2X/6-311++G(d,p) method has been used to obtain vibrational frequencies ${ }^{30-33}$ and have proved to be one of the best density functionals for non-covalent interactions. ${ }^{34}$ In addition, there is already a scale factor calculated ${ }^{35,36}$ for vibrational wavenumbers obtained using it. The starting geometries considered were those provided by the CIF file of each molecule. VEDA 4 program ${ }^{37}$ and Gauss View package ${ }^{38}$ were used to obtain the suggested vibrational frequency assignments. To obtain more coherent values between theoretical and experimental wavenumbers, the vibrational frequencies were scaled using as scale factor ${ }^{35} 0.9489$. In general, the scale factor equation is represented by ${ }^{39}$

$\varepsilon_{\mathrm{vib}}^{\mathrm{G}} \cong \frac{\hbar \mathrm{c}}{2} \sum_{m}\left(\lambda \omega_{m}\right)$

where $\varepsilon_{\mathrm{vib}}^{\mathrm{G}}$ is the harmonic approximation, $\omega_{\mathrm{m}}$ is the computed harmonic vibrational frequency of mode $m$ in wavenumber, $\hbar$ is Planck's constant. The scale factor is the constant $\lambda$.

The frontier molecular orbitals (FMO) and molecular electrostatic potential map (MEP) calculations were performed at same level of theory and, to comprehend reactional aspects of these molecules, the HOMO-LUMO energy gap, softness and hardness were obtained, as previously described. ${ }^{40}$

\section{Results and Discussion}

\section{Solid state characterization}

The molecule NMQ possesses a $p$-methoxyphenyl group connected to the chiral center C10 and an $o$-nitrobenzylidene group connected to a $\alpha-\beta$ insaturation in relation to ketone. A similar pattern occurs with the molecule CMQ, which has an $o$-methoxyphenyl group connect at atom $\mathrm{C} 10$ and an $o$-chlorobenzylidene group connected to ketonic ring. Both molecules have a phenylsulfonyl group connected to the nitrogen present in the heterocyclic ring of the quinolinone, constituting a backbone together with the benzene ring connected to $\mathrm{C} 5$ and C6 atoms. The NMQ and CMQ crystals are formed

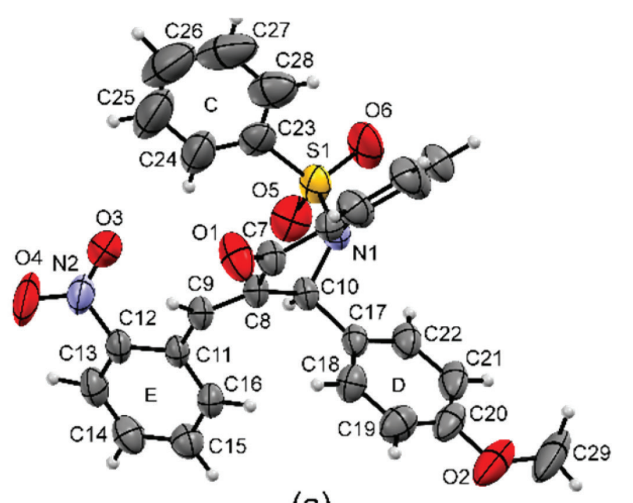

(a)

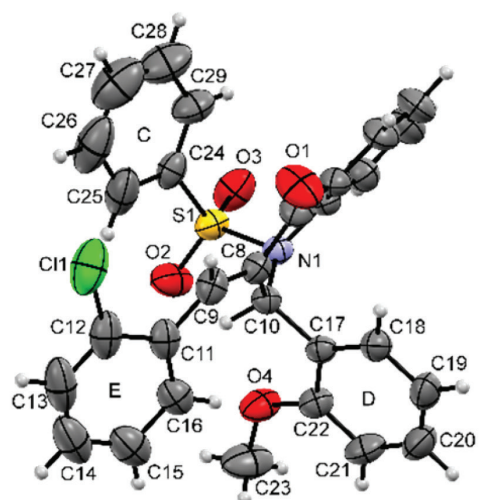

(c)

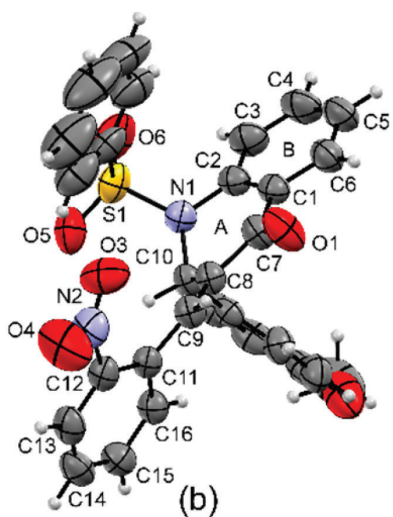

(b)

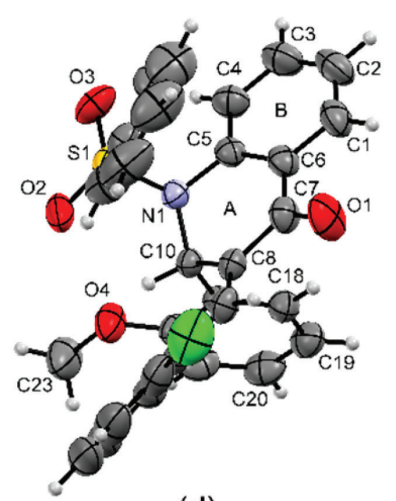

(d)

Figure 1. Ortep representation of the asymmetric units with 50\% probability of NMQ (a, b) and CMQ (c, d) from two perspectives. 
by a pair of enantiomers that have a chiral center located at carbon 10 (Figure 1). Both molecules crystallized in the centrosymmetric group P21/c with one molecule in the asymmetric unit, and for molecules at the unit cell. Figure 1 shows the Ortep representation of the $R$-enantiomer, arbitrarily chosen as asymmetric unit. The resume of crystallographic information of the analyzed compounds is described in Table 1. The intermolecular interactions data for NMQ are shown in Table 2.

Interactions of the type $\mathrm{C}-\mathrm{H} \cdots \pi$ and $\pi \cdots \pi$ were also identified as non-classical interactions and are described in Table 3. The non-classical interactions are indicated on Figure 2.
There is a bifurcated interaction $\mathrm{C} 15-\mathrm{H} 15 \cdots \mathrm{O} 4$ and C29-H29B …O 4 which forms a line of molecules in the direction of $\mathrm{c}$ axis, alternating between $\mathrm{R}$ and $\mathrm{S}$ enantiomers, as shown in Figure 3. Figure 3 also shows how these lines are interconnected by the contacts $\mathrm{C} 13-\mathrm{H} 13 \cdots \mathrm{O} 6$, forming a layer along the plane $\overrightarrow{(a c)}$. Each layer interacts with its inverse layer by means of the dimers formed by the contact C9-H9 ․ㅣ (Figure 4). The structure occurs by stacking these pairs of layers in the direction of $b$ axis. Figure 4 shows the packaging of the crystal.

From the graphical analysis of NMQ HS, it was verified that the most dominant interactions correspond to the contacts $\mathrm{C} 13-\mathrm{H} 13 \cdots \mathrm{O} 6$ and $\mathrm{C} 15-\mathrm{H} 15 \cdots \mathrm{O} 4$. The other

Table 1. Refinement, structure and crystal data for the compounds NMQ and CMQ

\begin{tabular}{|c|c|c|}
\hline & NMQ & CMQ \\
\hline Empirical formula & $\mathrm{C}_{29} \mathrm{H}_{23} \mathrm{~N}_{2} \mathrm{O}_{6} \mathrm{~S}$ & $\mathrm{C}_{29} \mathrm{H}_{23} \mathrm{ClN}_{1} \mathrm{O}_{4} \mathrm{~S}$ \\
\hline Formula weight / $\left(\mathrm{g} \mathrm{mol}^{-1}\right)$ & 527.6 & 515.98 \\
\hline Temperature / K & $296(2)$ & $296(2)$ \\
\hline Crystal system, space group & monoclinic, $\mathrm{P} 21 / \mathrm{c}$ & monoclinic, $\mathrm{P} 21 / \mathrm{c}$ \\
\hline \multirow[t]{4}{*}{ Unit cell dimensions } & $a=9.4515(9) \AA$ & $a=11.2257(7) \AA$ \\
\hline & $b=19.3086(16) \AA$ & $b=10.4938(5) \AA$ \\
\hline & $c=14.5216(12) \AA$ & $c=21.4824(12) \AA$ \\
\hline & $\beta=102.448(3)^{\circ}$ & $\beta=95.295(2)^{\circ}$ \\
\hline Volume / $\AA^{3}$ & 2587.82 & $2519.8(2)$ \\
\hline Z, calculated density & $4,1.35 \mathrm{~g} \mathrm{~cm}^{-3}$ & $4,1.360 \mathrm{mg} \mathrm{m}^{-3}$ \\
\hline Absorption coefficient $/ \mathrm{mm}^{-1}$ & 0.172 & 1.859 \\
\hline $\mathrm{F}(000)$ & 1100.0 & 1072 \\
\hline Cell measurement theta / degree & 1.8 to 25.0 & 1.82 to 26.43 \\
\hline \multirow[t]{3}{*}{$h k l$ indices } & $-10 \leq h \leq 11$ & $-14 \leq h \leq 13$ \\
\hline & $-22 \leq k \leq 22$ & $-13 \leq k \leq 13$ \\
\hline & $-17 \leq l \leq 17$ & $-26 \leq l \leq 25$ \\
\hline Reflections collected / independent & $87505 / 5296$ & $29845 / 4019$ \\
\hline Refinement method & $\min$ square $F^{2}$ & min square $F^{2}$ \\
\hline Goodness-of-fit (goof) & 1.122 & 1.058 \\
\hline \multirow[t]{2}{*}{ Final indices R [I > 2 (I)] } & $\mathrm{R}_{1}=0.0442$ & $\mathrm{R}_{1}=0.0517$ \\
\hline & $\mathrm{wR}_{2}=0.114$ & $\mathrm{Rw}_{2}=0.1439$ \\
\hline \multirow[t]{2}{*}{$\mathrm{R}$ indices (all data) } & $\mathrm{R}_{1}=0.0564$ & $\mathrm{R}_{1}=0.0673$ \\
\hline & $w R_{2}=0.130$ & $\mathrm{Rw}_{2}=0.1578$ \\
\hline
\end{tabular}

NMQ: (E)-3-(2-nitrobenzylidene)-2-(4-methoxyphenyl)-1-(phenylsulfonyl)-2,3-dihydroquinolin-4(1H)-one; CMQ: (E)-3-(2-chlorobenzylidene)2-(2-methoxyphenyl)-1-(phenylsulfonyl)-2,3-dihydroquinolin-4(1H)-one.

Table 2. Intermolecular interactions of NMQ, with distances and angles between the donor atom, hydrogen and acceptor atom

\begin{tabular}{lcccccc}
\hline Code & $\mathrm{D}-\mathrm{H} \cdots \mathrm{A}$ & $\mathrm{d}_{\mathrm{D}-\mathrm{H}} / \AA$ & $\mathrm{d}_{\mathrm{H} \cdots \mathrm{A}} / \AA$ & $\mathrm{d}_{\mathrm{D} \cdots \mathrm{A}} / \AA$ & $\theta_{\mathrm{D}-\mathrm{H} \cdots \mathrm{A}} /$ degree & Symmetry code \\
\hline $1 \mathrm{~N}$ & $\mathrm{C} 15-\mathrm{H} 15 \cdots \mathrm{O} 4$ & 0.966 & 2.527 & 3.126 & 120.18 & $\mathrm{x}, 1.5-\mathrm{y},-1 / 2+\mathrm{z}$ \\
$2 \mathrm{~N}$ & $\mathrm{C} 13-\mathrm{H} 13 \cdots \mathrm{O} 6$ & 0.974 & 2.358 & 3.130 & 135.73 & $-1+\mathrm{x}, 1.5-\mathrm{y},-1 / 2+\mathrm{z}$ \\
$3 \mathrm{~N}$ & $\mathrm{C} 29-\mathrm{H} 29 \mathrm{~B} \cdots \mathrm{O} 4$ & 0.921 & 2.701 & 3.271 & 120.88 & $\mathrm{x}, \mathrm{y},-1+\mathrm{z}$ \\
$4 \mathrm{~N}$ & $\mathrm{C} 9-\mathrm{H} 9 \cdots \mathrm{O} 1$ & 0.954 & 2.676 & 3.519 & 147.80 & $1-\mathrm{x}, 1-\mathrm{y}, 2-\mathrm{z}$ \\
\hline
\end{tabular}

NMQ: (E)-3-(2-nitrobenzylidene)-2-(4-methoxyphenyl)-1-(phenylsulfonyl)-2,3-dihydroquinolin-4(1H)-one; D: donor atom; A: acceptor atom; d: distance; $\theta$ : angle. 
Table 3. NMQ non-classical interactions $\mathrm{C}-\mathrm{H} \cdots \pi$ and $\pi \cdots \pi$

\begin{tabular}{lcc}
\hline Code & Intercation & Symmetry code \\
\hline $5 \mathrm{~N}$ & $\mathrm{NMQ}$ \\
$6 \mathrm{~N}$ & $\mathrm{C} 26-\mathrm{H} 26 \cdots \mathrm{C}_{\mathrm{g}} 1$ & $-\mathrm{x}, 1-\mathrm{y}, 2-\mathrm{z}$ \\
\hline
\end{tabular}

NMQ: (E)-3-(2-nitrobenzylidene)-2-(4-methoxyphenyl)-1(phenylsulfonyl)-2,3-dihydroquinolin-4(1H)-one.

interactions can be considered secondary, including the dimer formed by the contact C9-H9-..O1. It was probably due to the approximation caused by the packing, as well as the contact $\mathrm{C} 29-\mathrm{H} 29 \mathrm{~B} \cdots \mathrm{O} 4$, as they are not evidenced by the characteristic color of the most intense contacts, as shown in Figure 5.

With the Hirshfeld surface, it was possible to confirm some secondary interactions, such as $\mathrm{C} 26-\mathrm{H} 26 \cdots \mathrm{Cg} 1$ and $\mathrm{Cg} 2 \cdots \mathrm{Cg} 3$ (Figure 6).

Table 4 summarizes the non-classical and intermolecular interactions of CMQ.

There is a bifurcated interaction $\mathrm{C} 2-\mathrm{H} 2 \cdots \mathrm{O} 3$ and $\mathrm{C} 20-\mathrm{H} 20 \cdots \mathrm{O} 3$ which forms a line of molecules in the direction $(\overrightarrow{a b})$, and as also happens with NMQ bifurcated interactions, $\mathrm{C} 2-\mathrm{H} 2 \cdots \mathrm{O} 3$ and $\mathrm{C} 20-\mathrm{H} 20 \cdots \mathrm{O} 3$ alternated between $\mathrm{R}$ and $\mathrm{S}$ enantiomers, forming a centrosymmetric interaction. Between these inverse layers occurs an interaction provided by the dimer $\mathrm{C} 15-\mathrm{H} 15 \cdots \mathrm{O} 2$ (Figure 7).

The only non-classical interaction that occurs in CMQ molecule is centrosymmetric and it is between C14-H14 atoms and $\mathrm{Cg} 1$ ring forming a layer that stabilized the packing in $\overrightarrow{(a c)}$ direction, illustrated by Figure 8.

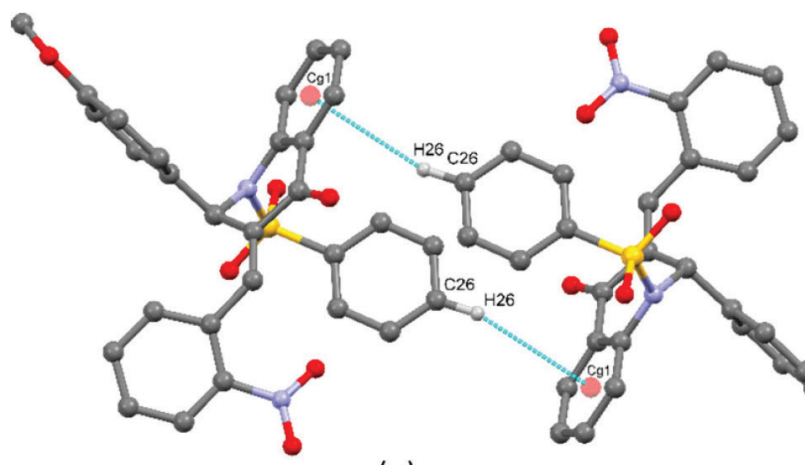

(a)

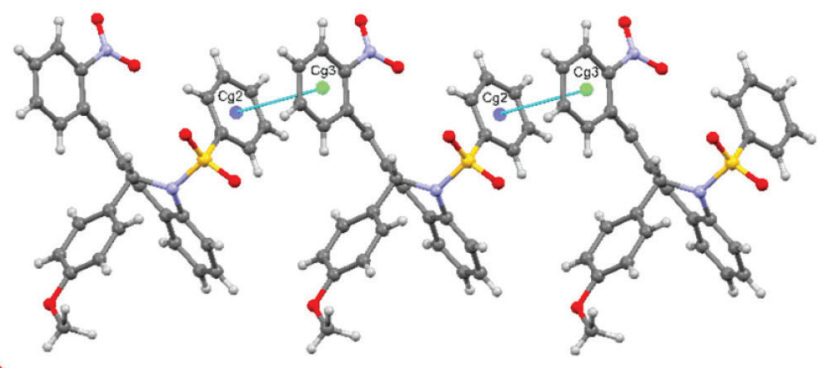

(b)

Figure 2. (a) NMQ non-classical interaction $\mathrm{C} 26-\mathrm{H} 26 \cdots \mathrm{C}_{\mathrm{g}} 1$; (b) NMQ non-classical interaction $\mathrm{C}_{\mathrm{g}} 2 \cdots \mathrm{C}_{\mathrm{g}} 3$.

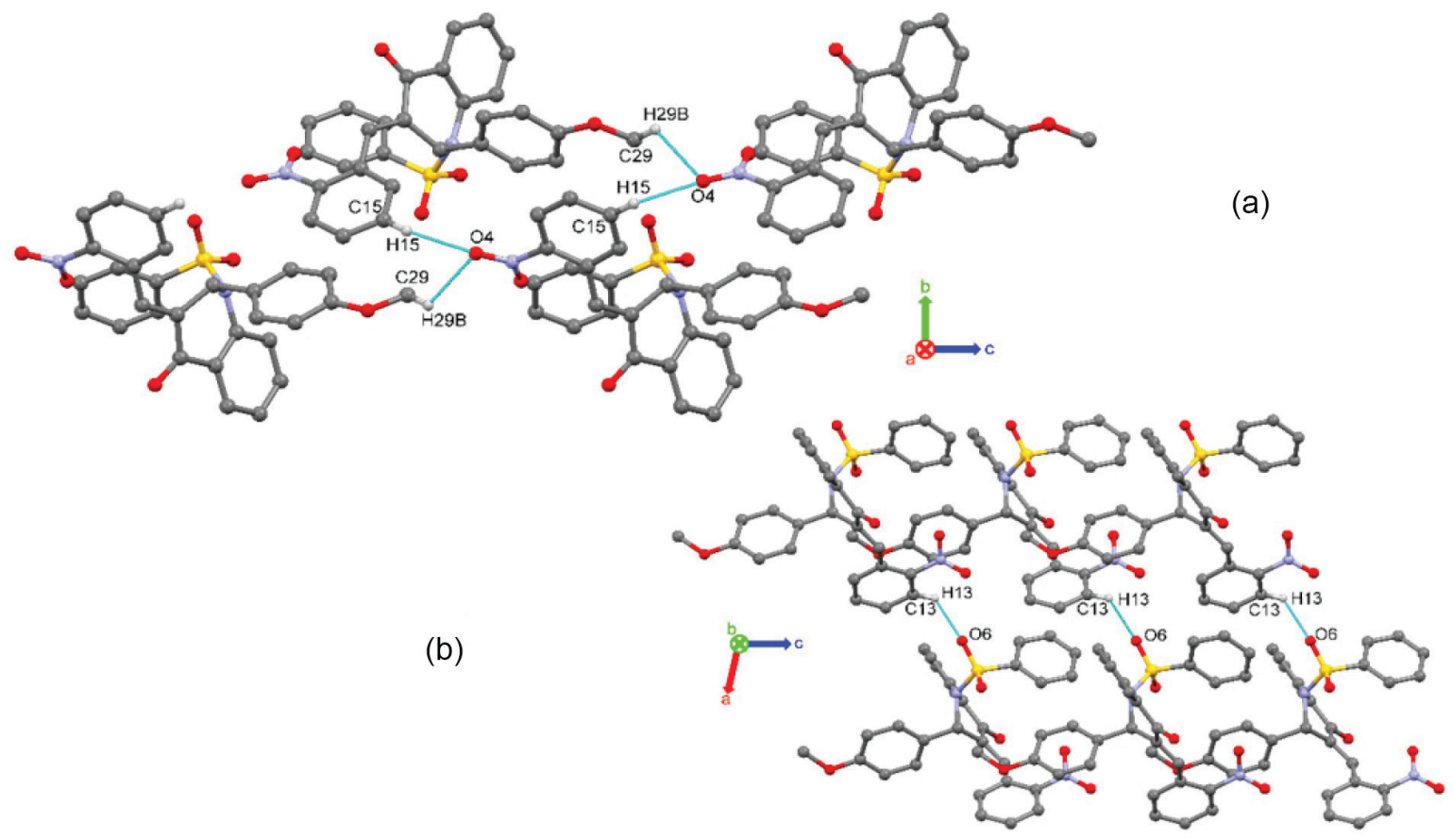

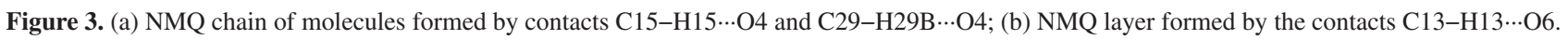




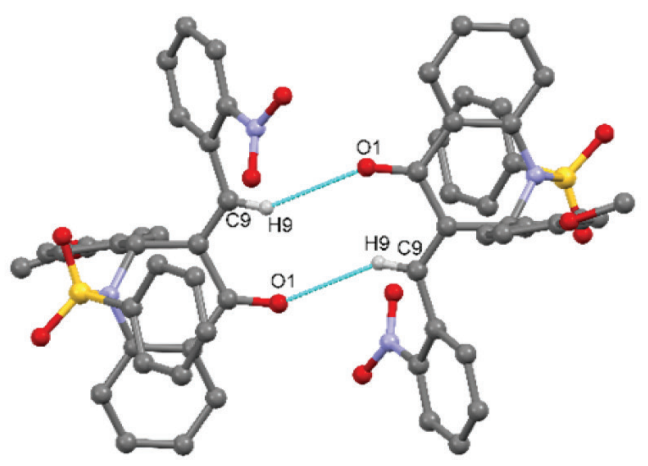

(a)

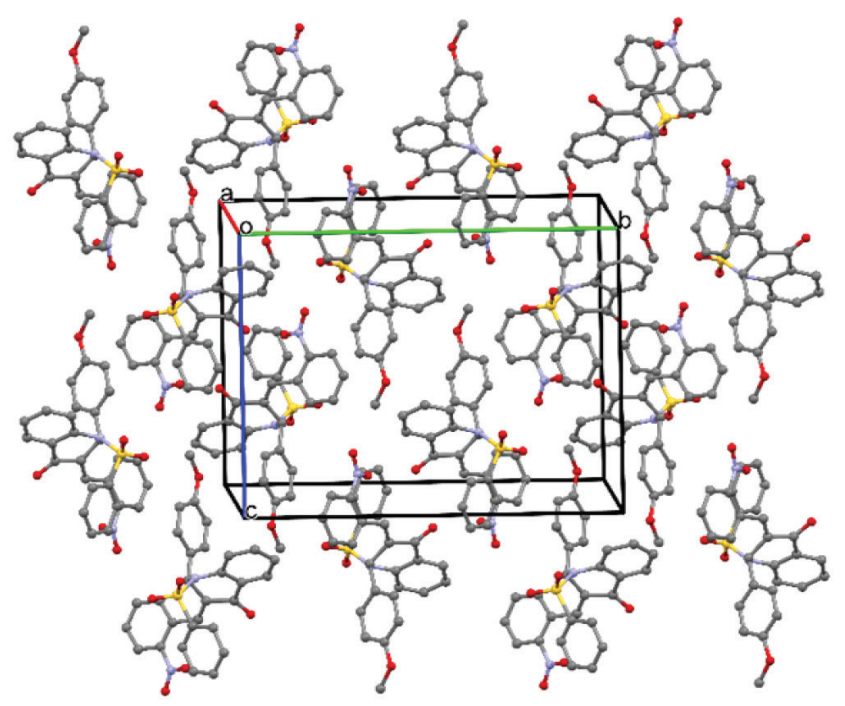

(b)

Figure 4. (a) NMQ dimer formed by interaction $\mathrm{C} 9-\mathrm{H} 9 \cdots \mathrm{O} 1$; (b) NMQ crystal packing.

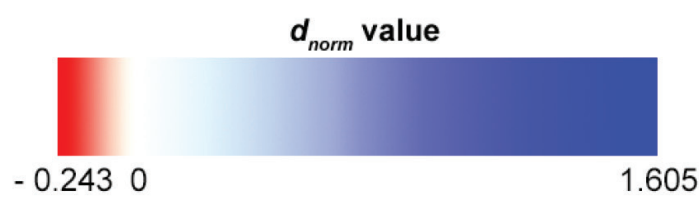

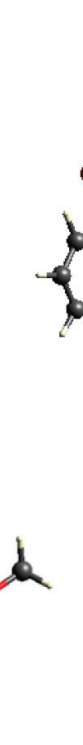

(a)

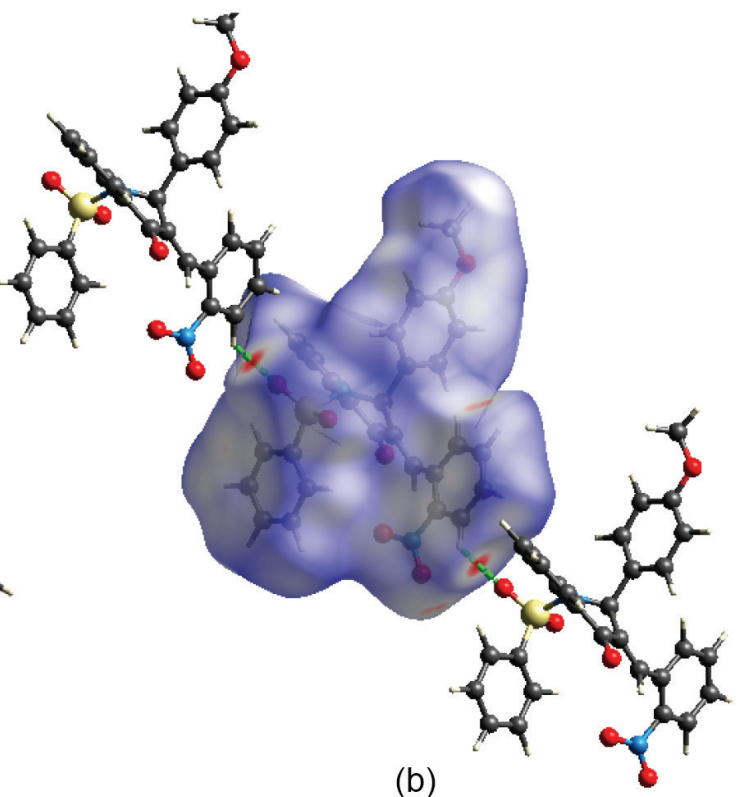

(b)

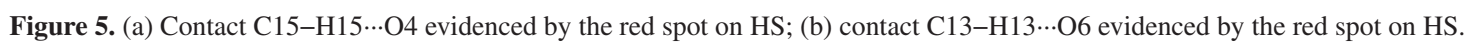

The CMQ structure occurs by stacking the layer formed by $\mathrm{C} 2-\mathrm{H} 2 \cdots \mathrm{O} 3$ and $\mathrm{C} 14-\mathrm{H} 14 \cdots \mathrm{O} 3$ in the direction of $\overrightarrow{(a c)}$ with the non-classical $\mathrm{C} 14-\mathrm{H} 14 \cdots \mathrm{Cg} 1$ and the dimer C15-H15 ‥O2 forming chains between the layers. The Figure 9 shows the packaging of the CMQ crystal.

It was verified, as well as NMQ molecule, from the graphical analysis of HS from CMQ, that the most dominant interactions correspond to the contacts $\mathrm{C} 2-\mathrm{H} 2 \cdots \mathrm{O} 3$. After that, the dimer $\mathrm{C} 15-\mathrm{H} 15 \cdots \mathrm{O} 2$, contributes with $18.2 \%$ of the interactions of the system. The other bifurcated interaction can be considered secondary, $\mathrm{C} 20-\mathrm{H} 20 \cdots \mathrm{O} 3$, which was probably due to the approximation caused by the packing as it is not evidenced by the characteristic color of the most intense contacts, as shown in Figure 10.

Unlike the NMQ molecule, when using the shape index analysis for CMQ, it was not noticeable $\pi \cdots \pi$ contacts, bought by the low percentage of $\mathrm{C} \cdots \mathrm{C}$ interactions indicating fingerprint with value of $3.6 \%$ and elevated distance $(3.9 \AA$ ) between the rings of the sulfonyl group. Additionally, the non-classical interaction C14-H14 ‥ Cg1 can be seen in Figure 11 contributing with $18 \%$ of the stabilizing packing system, proven by the fingerprint analysis. 

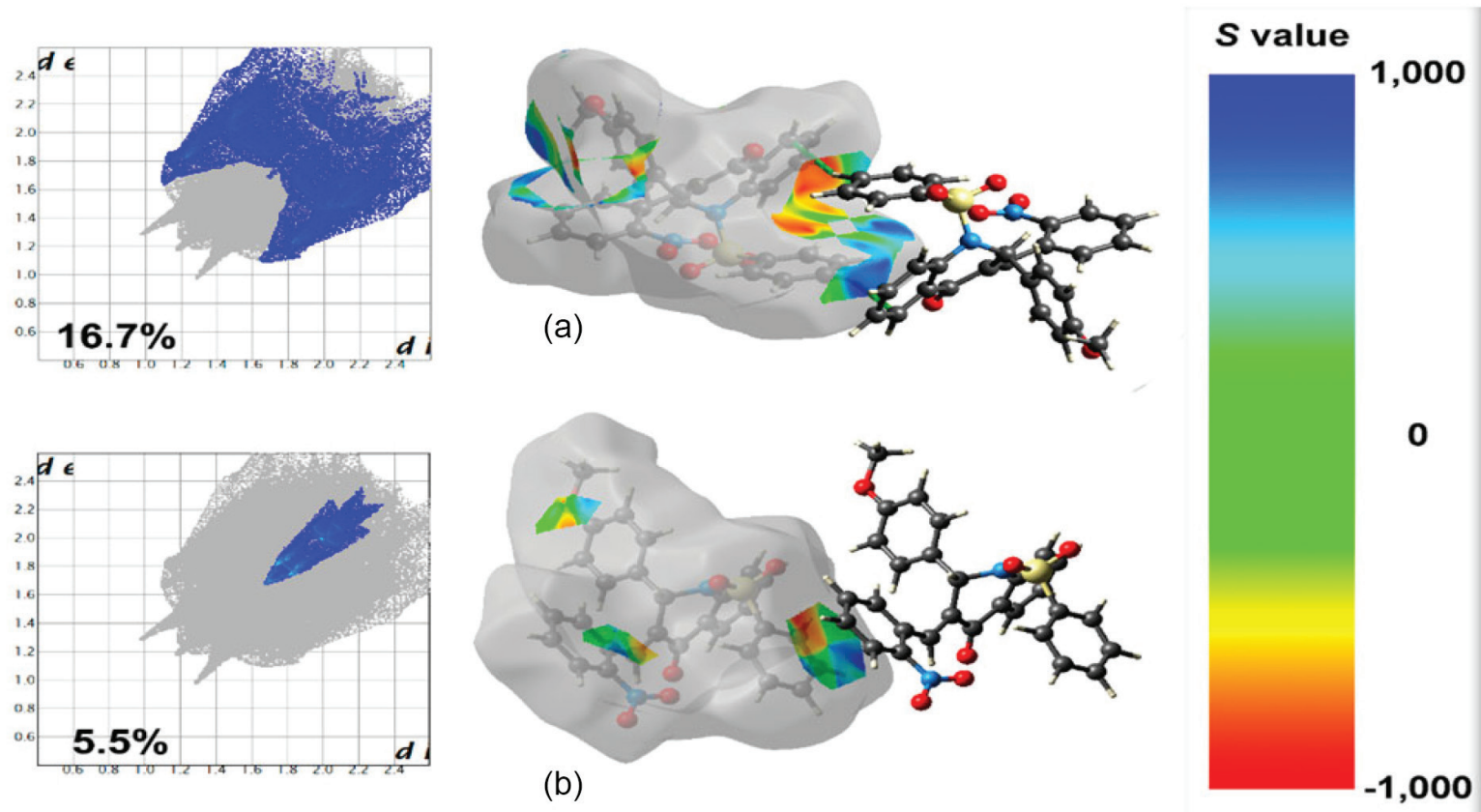

(b)

Figure 6. Fingerprint and Hirshfeld surface of the asymmetric unit revealing the contacts $\mathrm{H} \cdots \mathrm{C}$ (a) and C‥C (b), including reciprocal contacts.

Table 4. Non-classical and intermolecular interactions of CMQ, with distances (d) and angles ( $\theta$ ) between the donor atom (D), hydrogen and acceptor atom (A)

\begin{tabular}{|c|c|c|c|c|c|c|}
\hline \multicolumn{7}{|c|}{ CMQ intermolecular interaction } \\
\hline Code & $\mathrm{D}-\mathrm{H} \cdots \mathrm{A}$ & $\mathrm{d}_{\mathrm{D}-\mathrm{H}} / \AA$ & $\mathrm{d}_{\mathrm{H} \cdots \mathrm{A}} / \AA$ & $\mathrm{d}_{\mathrm{D} \cdots \mathrm{A}} / \AA$ & $\theta_{\mathrm{D}-\mathrm{H} \cdots \mathrm{A}} /$ degree & Symmetry code \\
\hline $1 \mathrm{C}$ & $\mathrm{C} 15-\mathrm{H} 15 \cdots \mathrm{O} 2$ & 0.930 & 2.547 & 3.233 & 130.90 & $-\mathrm{x}, 1-\mathrm{y}, 1-\mathrm{z}$ \\
\hline $2 \mathrm{C}$ & $\mathrm{C} 2-\mathrm{H} 2 \cdots \mathrm{O} 3$ & 0.930 & 2.444 & 3.350 & 164.67 & $1-\mathrm{x},-1 / 2+\mathrm{y}, 1 / 2-\mathrm{z}$ \\
\hline $3 \mathrm{C}$ & $\mathrm{C} 20-\mathrm{H} 20 \cdots \mathrm{O} 3$ & 0.930 & 2.667 & 3.441 & 141.15 & $-\mathrm{x},-1 / 2+\mathrm{y}, 1 / 2-\mathrm{z}$ \\
\hline \multicolumn{7}{|c|}{ CMQ non-classical intermolecular interaction } \\
\hline Code & \multicolumn{3}{|c|}{ Interaction } & & \multicolumn{2}{|c|}{ Symmetry code } \\
\hline $4 \mathrm{C}$ & \multicolumn{3}{|c|}{$\mathrm{C} 14-\mathrm{H} 14 \cdots \mathrm{Cg} 1$} & & \multicolumn{2}{|c|}{$\mathrm{x}, 1 / 2-\mathrm{y}, 1 / 2+\mathrm{z}$} \\
\hline
\end{tabular}

CMQ: (E)-3-(2-chlorobenzylidene)-2-(2-methoxyphenyl)-1-(phenylsulfonyl)-2,3-dihydroquinolin-4(1H)-one.

\section{Theoretical analysis}

In Table 5, the experimental and theoretical vibrational wavenumbers and theoretical infrared intensities are presented. The assignments presented show a good agreement between the theoretical scaled wavenumbers and the experimental values, thus, we expect reliability of the obtained band assignments. A brief discussion is given for vibrations of the main groups in CNQ and NMQ structures.

In the studied compounds, we have two types of double bonds between carbons; the first is found in the aromatic rings and the other in the vinyl group. For $v(\mathrm{C}=\mathrm{C})$ in aromatic rings, bands are expected at 1600 to $1475 \mathrm{~cm}^{-1}$ and for vinyl group, when conjugated with carbonyl group, between 1660 and $1600 \mathrm{~cm}^{-1}{ }^{41}$ For CMQ, the
$v(\mathrm{C}=\mathrm{C})$ vibrations in aromatic rings are found at 1599 to $1463 \mathrm{~cm}^{-1}$ and 1590 to $1551 \mathrm{~cm}^{-1}$ in experimental and calculated spectra, respectively. On the other hand, for NMQ, these vibrational modes occur at 1607 to $1458 \mathrm{~cm}^{-1}$ (experimental) and at 1601 to $1554 \mathrm{~cm}^{-1}$ (calculated). The (C-C) stretching in vinyl group for CMQ is observed at $1599 \mathrm{~cm}^{-1}$ in experimental spectra and calculated at $1623 \mathrm{~cm}^{-1}$. In NMQ, these vibrations are assigned at 1607 and $1625 \mathrm{~cm}^{-1}$, respectively.

The carbonyl group absorbs in the range from 1850 to $1650 \mathrm{~cm}^{-1}$, but conjugation effects, such as those occurring in title compounds, result in a dropping of the $(\mathrm{C}=\mathrm{O})$ frequency. ${ }^{41}$ The band at 1668 and at $1676 \mathrm{~cm}^{-1}$, in IR spectrum, and the scaled frequencies at 1710 and 1714 $\mathrm{cm}^{-1}$ are assigned to $\mathrm{v}(\mathrm{C}=\mathrm{O})$ vibration in CMQ and NMQ, respectively. For $\mathrm{SO}_{2}$ group, in sulfonamide moiety, an 


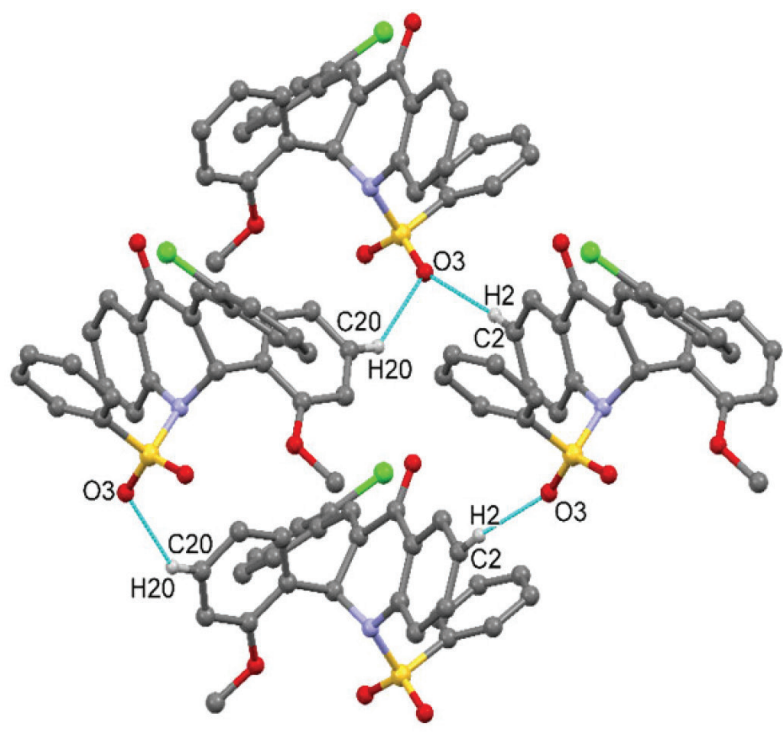

(a)

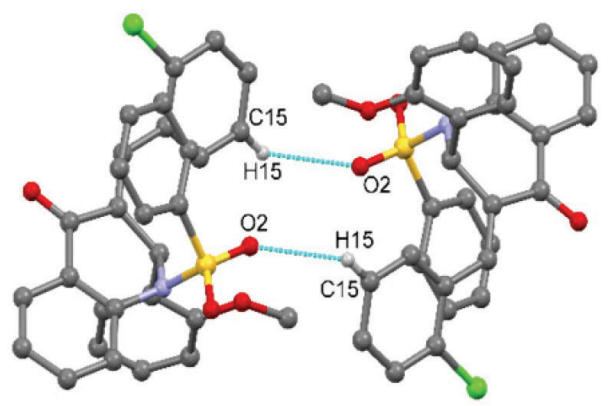

(b)

Figure 7. (a) CMQ chain of molecules formed by contacts $\mathrm{C} 2-\mathrm{H} 2 \cdots \mathrm{O} 3$ and $\mathrm{C} 20-\mathrm{H} 20 \cdots \mathrm{O} 3$ growing in the direction [110]; (b) CMQ dimer formed by interaction $\mathrm{C} 15-\mathrm{H} 15 \cdots \mathrm{O} 2$.

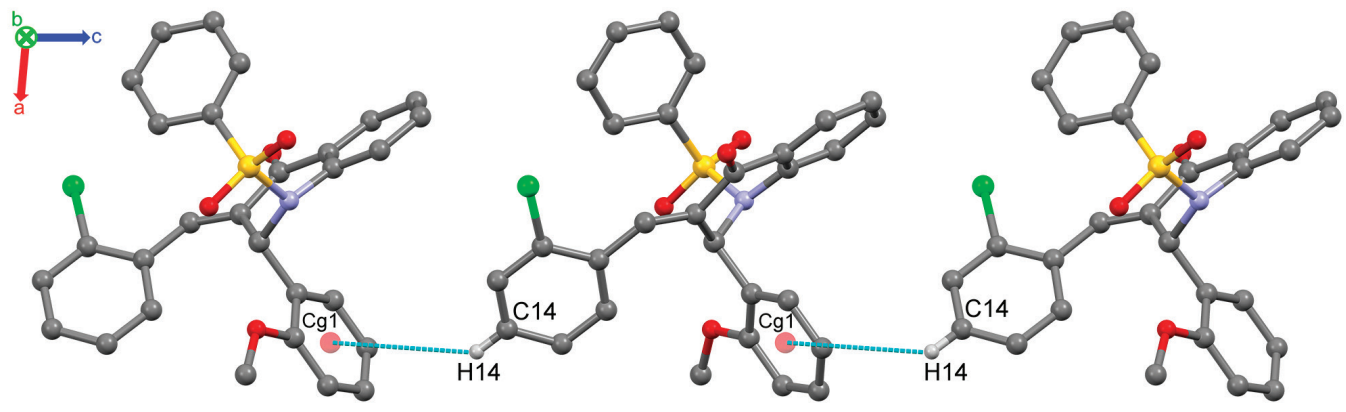

Figure 8. CMQ non-classical interaction $\mathrm{C} 14-\mathrm{H} 14 \cdots \mathrm{Cg} 1$ growing at [101] direction.

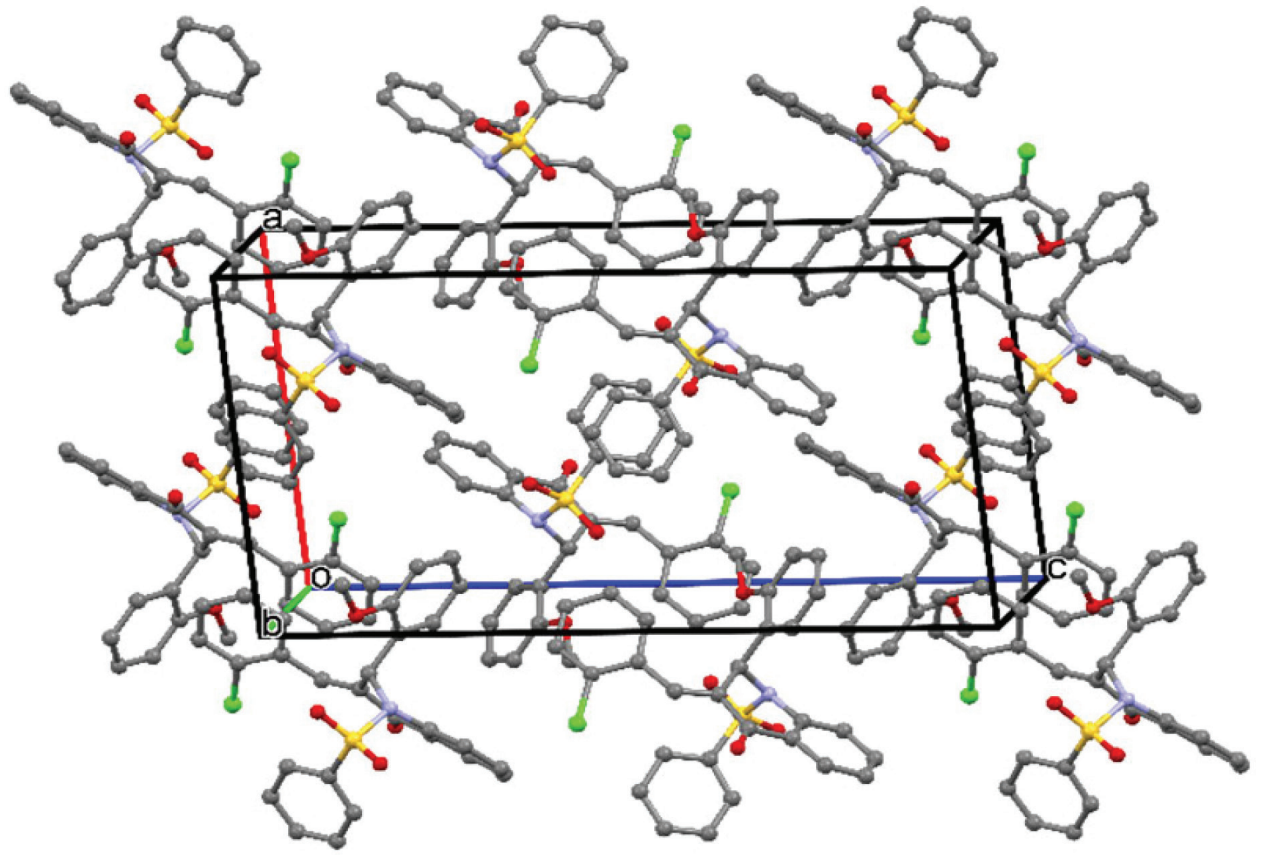

Figure 9. CMQ crystal packing. 


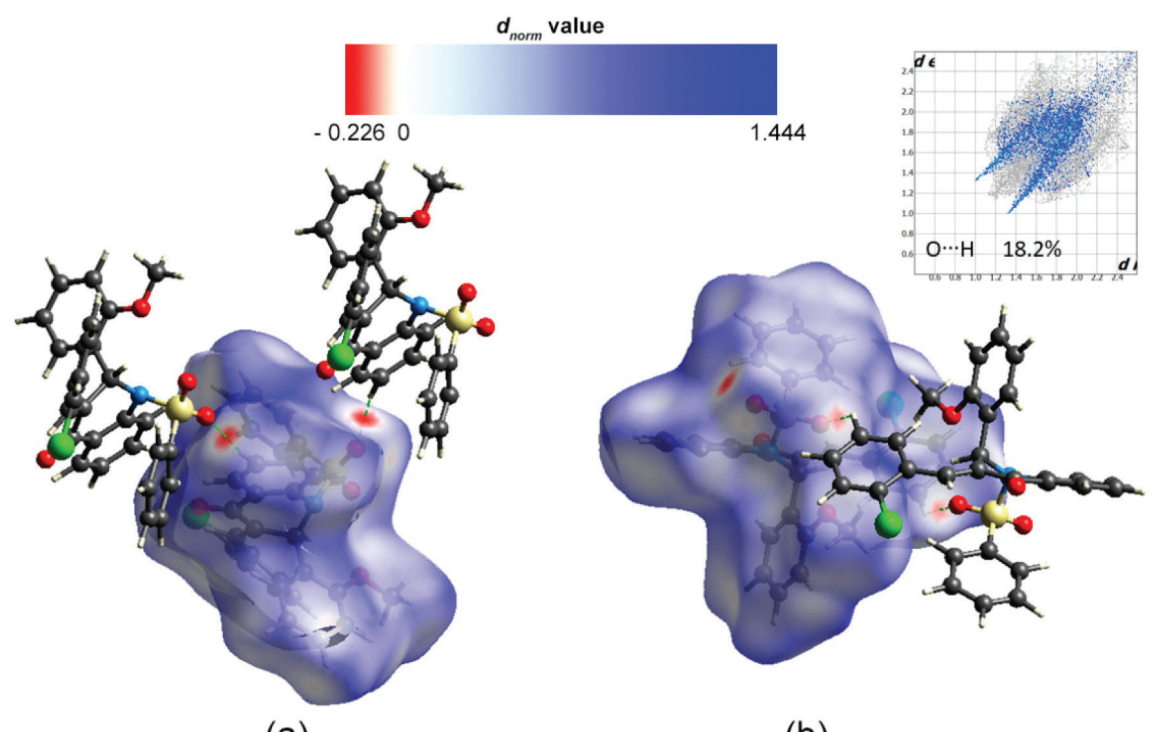

(a)

(b)

Figure 10. Hirshfield surface $\mathrm{d}_{\text {norm }}$ for $\mathrm{CMQ}$ molecule: (a) contact $\mathrm{C} 2-\mathrm{H} 2 \cdots \mathrm{O} 3$; (b) contact $\mathrm{C} 15-\mathrm{H} 15 \cdots \mathrm{O} 2$ evidenced by the red spots and fingerprint for $\mathrm{O} \cdots \mathrm{H}$ interactions including reciprocal contacts.

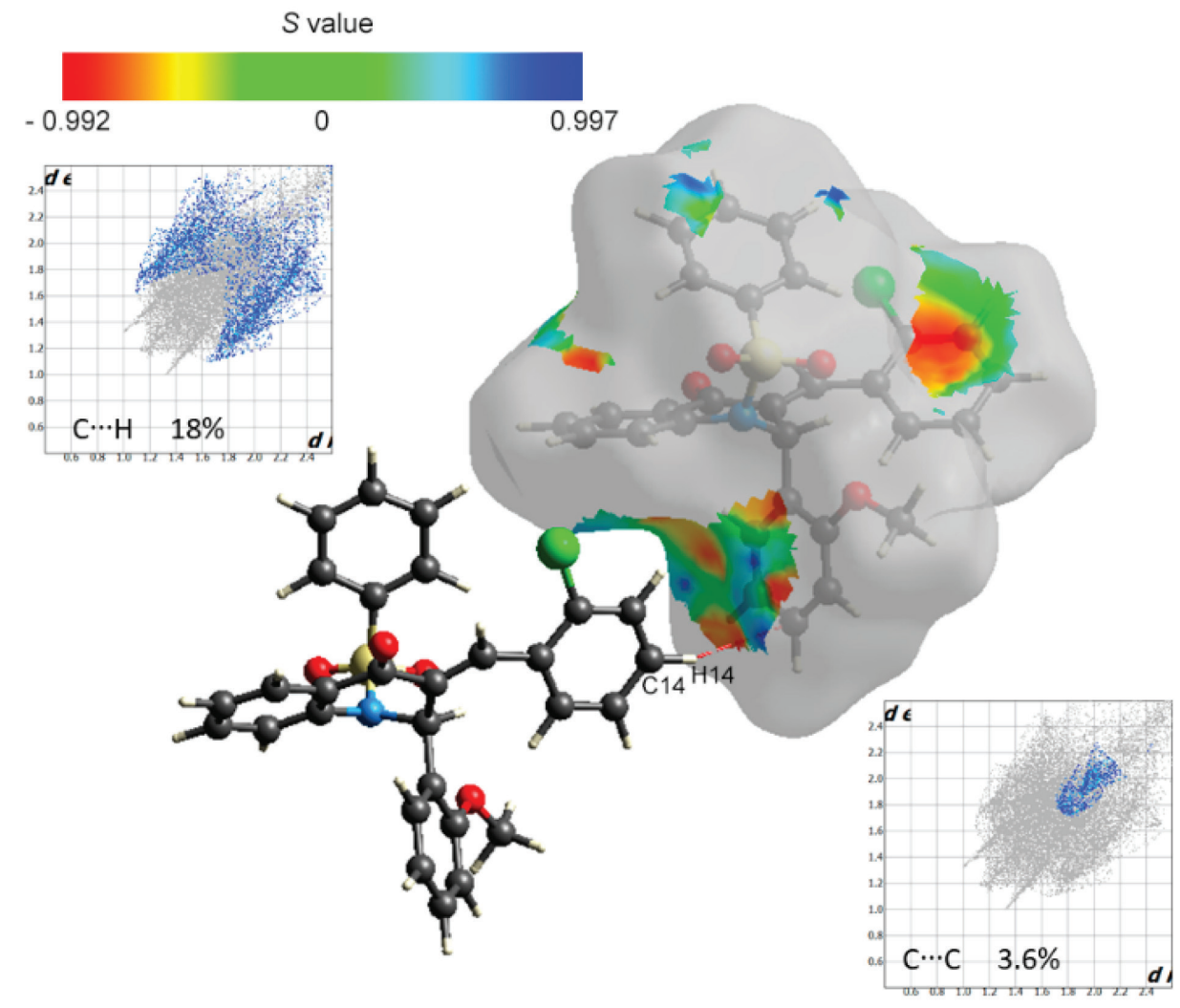

Figure 11. Hirshfield surface shape index for CMQ molecule illustrating the contact $\mathrm{C} 14-\mathrm{H} 14 \cdots \mathrm{Cg} 1$ and fingerprint for $\mathrm{C} \cdots \mathrm{H}$ and $\mathrm{H} \cdots \mathrm{H}$ interactions including reciprocal contacts.

asymmetrical stretching band occurs at $1325 \mathrm{~cm}^{-1}$, while the symmetrical stretching band appears in the region of $1140 \mathrm{~cm}^{-1} .{ }^{29}$ In the title molecules, the scaled frequencies at 1299 and at $1298 \mathrm{~cm}^{-1}$ have been assigned to asymmetric stretching and the scaled frequencies at 1111 and at $1113 \mathrm{~cm}^{-1}$ have been assigned to symmetric stretching mode of $\mathrm{SO}_{2}$ group in $\mathrm{CMQ}$ and $\mathrm{NMQ}$, respectively. In the experimental spectra, the band of asymmetric $\mathrm{vSO}_{2}$ mode appears at 1359 and $1349 \mathrm{~cm}^{-1}$, in CMQ and NMQ, respectively, while symmetric stretching vibration appears at $1165 \mathrm{~cm}^{-1}$ for both compounds.

The conjugation of $\mathrm{NO}_{2}$ group with an aromatic 
Table 5. Vibrational assignments, experimental and calculated wavenumbers of CMQ (I) and NMQ (II)

\begin{tabular}{|c|c|c|c|c|}
\hline Vibrational mode & Unscaled IR freq. & IR intensity / $\left(\mathrm{km} \mathrm{mol}^{-1}\right)$ & Scaled IR freq. ${ }^{a}$ & IR observed $/ \mathrm{cm}^{-1}$ \\
\hline$v(\mathrm{C}-\mathrm{C})_{\mathrm{Ar}}$ & $\begin{array}{l}\text { (I) } 1676-1635 \\
\text { (II) } 1687-1638\end{array}$ & - & $\begin{array}{l}\text { (I) } 1590-1551 \\
\text { (II) } 1601-1554\end{array}$ & $\begin{array}{l}\text { (I) } 1599-1463 \\
\text { (II) } 1607-1458\end{array}$ \\
\hline$v(\mathrm{C}=\mathrm{C})$ & $\begin{array}{l}\text { (I) } 1710 \\
\text { (II) } 1713\end{array}$ & $\begin{array}{l}\text { (I) } 159.33 \\
\text { (II) } 63.24\end{array}$ & $\begin{array}{l}\text { (I) } 1623 \\
\text { (II) } 1625\end{array}$ & $\begin{array}{l}\text { (I) } 1599 \\
\text { (II) } 1607\end{array}$ \\
\hline$v(\mathrm{C}=\mathrm{O})$ & $\begin{array}{l}\text { (I) } 1802 \\
\text { (II) } 1806\end{array}$ & $\begin{array}{l}\text { (I) } 141.65 \\
\text { (II) } 137.65\end{array}$ & $\begin{array}{l}\text { (I) } 1710 \\
\text { (II) } 1714\end{array}$ & $\begin{array}{l}\text { (I) } 1668 \\
\text { (II) } 1676\end{array}$ \\
\hline$v_{\text {asym }} \mathrm{SO}_{2}$ & $\begin{array}{l}\text { (I) } 1369 \\
\text { (II) } 1368\end{array}$ & $\begin{array}{l}\text { (I) } 200.52 \\
\text { (II) } 171.67\end{array}$ & $\begin{array}{l}\text { (I) } 1299 \\
\text { (II) } 1298\end{array}$ & $\begin{array}{l}\text { (I) } 1359 \\
\text { (II) } 1349\end{array}$ \\
\hline$v_{\mathrm{sym}} \mathrm{SO}_{2}$ & $\begin{array}{l}\text { (I) } 1171 \\
\text { (II) } 1173\end{array}$ & $\begin{array}{l}\text { (I) } 172.92 \\
\text { (II) } 179.34\end{array}$ & $\begin{array}{l}\text { (I) } 1111 \\
\text { (II) } 1113\end{array}$ & $\begin{array}{l}\text { (I) } 1165 \\
\text { (II) } 1165\end{array}$ \\
\hline$v_{\text {asym }} \mathrm{NO}_{2}$ & (II) 1703 & (II) 418 & (II) 1616 & (II) 1525 \\
\hline$v_{\text {sym }} \mathrm{NO}_{2}$ & (II) 1466 & (II) 197 & (II) 1391 & (II) 1349 \\
\hline$v\left(\mathrm{O}-\mathrm{CH}_{3}\right)$ & $\begin{array}{l}\text { (I) } 1147 \\
\text { (II) } 1109\end{array}$ & $\begin{array}{l}\text { (I) } 56.87 \\
\text { (II) } 33.63\end{array}$ & $\begin{array}{l}\text { (I) } 1088 \\
\text { (II) } 1052\end{array}$ & $\begin{array}{l}\text { (I) } 1027 \\
\text { (II) } 1030\end{array}$ \\
\hline$v(\mathrm{C}-\mathrm{Cl})$ & (I) 1066 & (I) 47.35 & (I) 1012 & (I) 1027 \\
\hline
\end{tabular}

${ }^{a}$ Scale factor 0.9489; v: stretching; I: CMQ ((E)-3-(2-chlorobenzylidene)-2-(2-methoxyphenyl)-1-(phenylsulfonyl)-2,3-dihydroquinolin-4(1H)-one); II: NMQ (E)-2-(4-methoxyphenyl)-3-(2-nitrobenzylidene)-1-(phenylsulfonyl)-2,3-dihydroquinolin-4(1H)-one.

ring moves its stretch frequency in a range of 1550 to $1490 \mathrm{~cm}^{-1}$, for asymmetric mode and 1355 to $1315 \mathrm{~cm}^{-1}$, for symmetric mode. ${ }^{41}$ Among the compounds present in this study, only NMQ has a nitro group present in its molecular structure. Therefore, the asymmetric stretching vibration is observed at $1525 \mathrm{~cm}^{-1}$ in the IR spectra and at $1616 \mathrm{~cm}^{-1}$ in calculated spectra. In relation to symmetric stretching vibration, it is observed at 1349 and $1391 \mathrm{~cm}^{-1}$ in experimental and calculated spectra, respectively. The $v\left(\mathrm{O}-\mathrm{CH}_{3}\right)$ mode appears in region ${ }^{42,43}$ at 850 to $1100 \mathrm{~cm}^{-1}$, so, in the experimental spectrum, this deformation appear in a band at $1027 \mathrm{~cm}^{-1}$, for CMQ, and at $1030 \mathrm{~cm}^{-1}$ for NMQ. In terms of scaled frequencies, these values are at 1088 and $1052 \mathrm{~cm}^{-1}$, respectively. Finally, in organic chlorine compounds, like $\mathrm{CMQ}$, the $\mathrm{v}(\mathrm{C}-\mathrm{Cl})$ frequencies appears in the region ${ }^{44}$ of $1129-480 \mathrm{~cm}^{-1}$. In this study, this scaled frequency appears at $1012 \mathrm{~cm}^{-1}$, while the experimental band appears at $1027 \mathrm{~cm}^{-1}$. The graphical representation of the observed and scaled calculated spectra of CMQ and NMQ are shown in Figure 12.

The results of molecular orbital geometry and molecular electrostatic potential map calculations are presented in Figure 13. In CMQ, HOMO orbital is distributed in the region of the anisole ring, while the LUMO orbital is widely distributed by dihydroquinoline nuclei and chlorobenzene regions. For NMQ, HOMO orbital is distributed over nitrobenzene, while LUMO is dispersed over dihydroquinoline nuclei and nitrobenzene.

Using the DFT values of energy of HOMO and LUMO orbitals, some global reactivity descriptors $\left(\mathrm{E}_{\text {gap }}\right.$, hardness and softness) were calculated. ${ }^{45}$ In a general way, it is know that larger HOMO-LUMO energy gap indicates more stable (less reactive) compounds. This measure can also be interpreted in terms of hardness and softness, in other
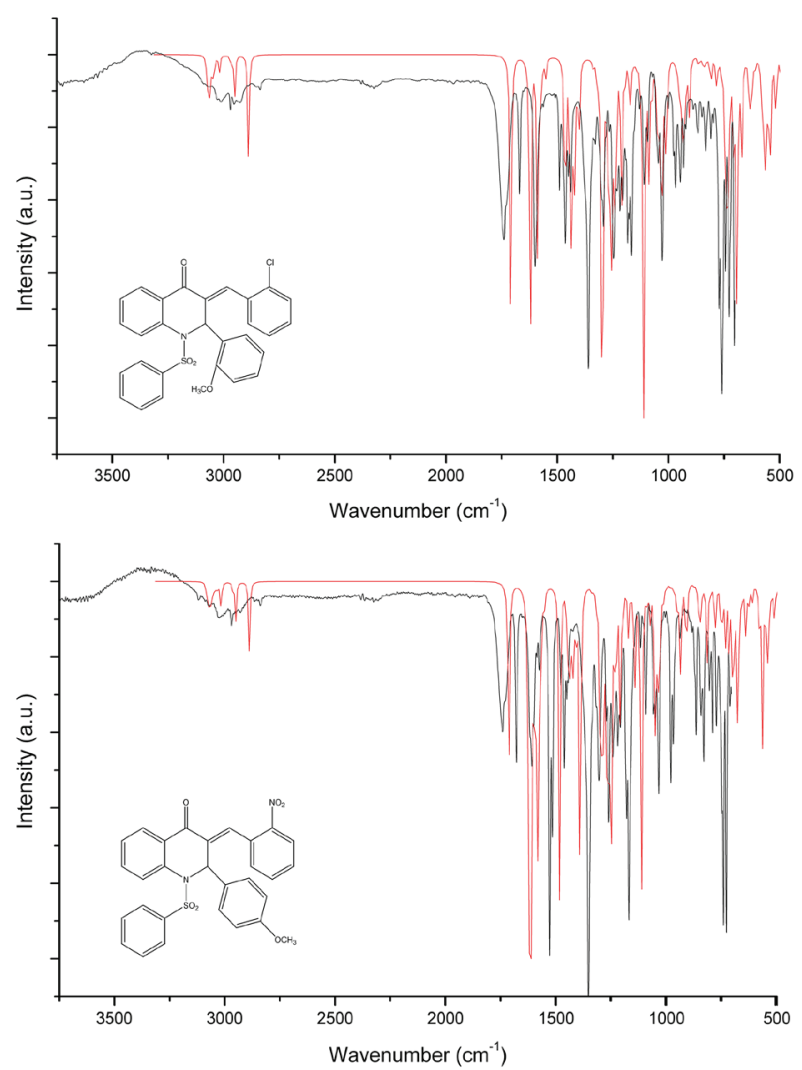

Figure 12. Overlapping of experimental (black) and scaled theoretical (red) IR spectra of CMQ (top) and NMQ (bottom). 


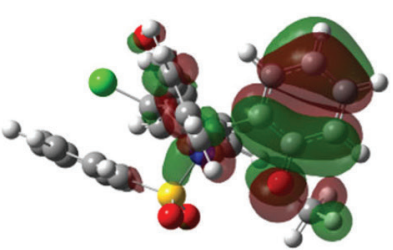

$E_{\text {LUMO }}=-1.84 \mathrm{eV}$

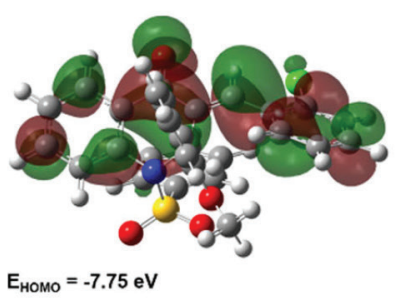

(a)

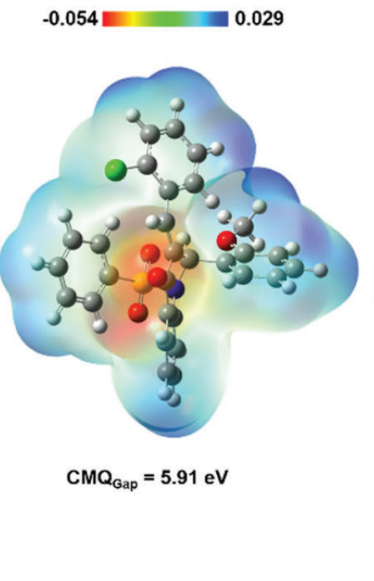

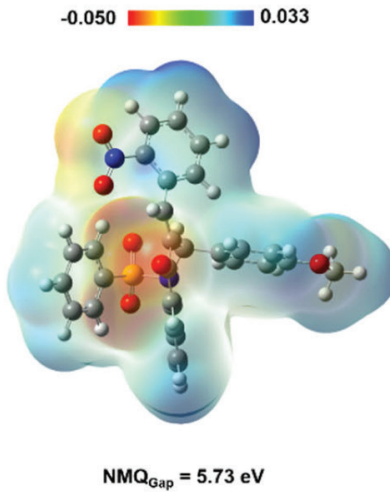

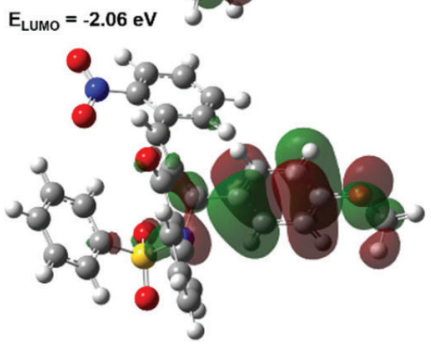

$E_{\text {номо }}=-7.79 \mathrm{eV}$

(b)

Figure 13. The HOMO, LUMO and MEP graphical representation for CMQ (a) and NMQ (b) molecules calculated using M06-2X/6-311++G(d,p) theory level.

words, the resistance of an atom to a charge transfer and the availability to receive electrons, respectively. ${ }^{45-47}$ The calculated energies for $\mathrm{E}_{\text {gap }}$, hardness and softness are, respectively: 5.91, 2.95 and $0.34 \mathrm{eV}$ for CMQ and 5.73, 2.86 and $0.35 \mathrm{eV}$ for NMQ. The high values of $\mathrm{E}_{\text {gap }}$ and hardness, when compared to NMQ, indicate that CMQ is, slightly more resistant to a charge transfer; it means, more electronic chemical stability. In relation of the capacity of both molecules to receive electrons (softness), we can expect the same behavior since the calculated values are almost equal.

The MEP analysis show high electron density sites (red regions), where are located the groups with $\mathrm{O}$ atoms. In CMQ, the local minimum on $\mathrm{SO}_{2}$ group is about -0.054 a.u. That value for $(\mathrm{C}=\mathrm{O})$ group is -0.047 a.u. and for $\left(\mathrm{O}-\mathrm{CH}_{3}\right)$ group is -0.041 a.u. From these results, it is possible to suggest a rank of sites that are most probable to suffer electrophiles attack as follow: $\mathrm{SO}_{2}>(\mathrm{C}=\mathrm{O})>$ $\left(\mathrm{O}-\mathrm{CH}_{3}\right)$. For NMQ that rank is: $\mathrm{SO}_{2}(-0.050$ a.u. $)>(\mathrm{C}=\mathrm{O})$ $(-0.042$ a.u. $)>\mathrm{NO}_{2}(-0.038$ a.u. $)>\left(\mathrm{O}-\mathrm{CH}_{3}\right)(-0.025$ a.u. $)$. On the other hand, low electron density sites (blue regions) are located at aromatic rings in both molecules. So, using the value of eletrostatic potential, it is possible to suggest a rank of sites that are most probable to suffer nucleophiles attack. That rank for CMQ is: methoxibenzene (0.027 a.u.) > cholorobenzene ( 0.023 a.u. $)>$ aromatic ring at dihydroquinolin-4(1H)-one nucleus $(0.020$ a.u.). For NMQ it is: nitrobenzene ( 0.033 a.u.) > methoxibenzene $(0.030$ a.u. $)>$ aromatic ring at dihydroquinolin- $4(1 H)$-one nucleus (0.022 a.u.).

\section{Conclusions}

Both NMQ and CMQ molecules crystallized in the monoclinic space group P21/c with similar volume and density, regarding their structural similarity. It is unmistakable, for both compounds, that the most contributing intramolecular interaction is of $\mathrm{O} \cdots \mathrm{H}$ kind. Another similarity is the presence of a dimer and a $\mathrm{C}-\mathrm{H} \cdots \pi$ interaction. Differences can be noted in the direction of the crystal packing, probably because the substituent group chlorine in CMQ and nitro in NMQ. Furthermore, the occurrence of a non-classical $\pi \cdots \pi$ interaction, present in NMQ and absent in CMQ, can be explained due the nitro group acting as an stronger electron withdrawal agent than chlorine, resulting in a larger approximation of the rings. The calculated IR spectra show a good agreement between theoretical and experimental values (correlation coefficient, $\mathrm{R}^{2}$, equal to 0.9611 ), so it was possible to assign the regions of absorptions of main groups in both structures. The HOMO and LUMO energies show CMQ more electronic stable than NMQ with a higher resistance to charge transfer. In addition, the regions near to $\mathrm{O}$ atoms have a higher electrophilic character while, aromatic rings have nucleophilic character.

\section{Supplementary Information}

${ }^{1} \mathrm{H}$ NMR, FTIR, melting point and yield of (E)-3-(2-nitrobenzylidene)-2-(4-methoxyphenyl)1-(phenylsulfonyl)-2,3-dihydroquinolin-4(1H)-one (5) and $(E)$-3-(2-chlorobenzylidene)-2-(2-methoxyphenyl)- 
1-(phenylsulfonyl)-2,3-dihydroquinolin-4(1H)-one (6) are available free of charge at http://jbcs.sbq.org.br as PDF file.

\section{Acknowledgments}

The authors would like to thank Brazilian funding agencies CNPq, CAPES and FAPEG for financial support and fellowships. Research was developed with support of the High-Performance Computing Center at the Universidade Estadual de Goiás (UEG). Single crystal X-ray diffraction data were collected at Instituto de Química de São Carlos (IQSC) of the Universidade de São Paulo (USP).

\section{References}

1. Nammalwar, B.; Bunce, R. A.; Molecules 2014, 19, 204.

2. Garg, M.; Chauhan, M.; Singh, P. K.; Alex, J. M.; Kumar, R.; Eur. J. Med. Chem. 2015, 97, 444.

3. Boteva, A. A.; Krasnykh, O. P.; Chem. Heterocycl. Compd. 2009, 45, 757.

4. Rodrigues-Silva, C.; Maniero, M. G.; Peres, M. S.; Guimarães, J. R.; Quim. Nova 2014, 37, 868.

5. Roussaki, M.; Hall, B.; Lima, S. C.; da Silva, A. C.; Wilkinson, S.; Detsi, A.; Bioorg. Med. Chem. Lett. 2013, 23, 6436.

6. Kwak, S. H.; Kim, M. J.; Lee, S. D.; You, H.; Kim, Y. C.; Ko, H.; ACS Comb. Sci. 2015, 17, 60.

7. Kwak, S. H.; Kang, J. A.; Kim, M.; Lee, S. D.; Park, J. H.; Park, S. G.; Ko, H.; Kim, Y. C.; Bioorg. Med. Chem. 2016, 24, 5357.

8. Sharma, K. L. N.; Kumar, C. S.; Kumaraswamy, S.; Reddy, V. K.; Rao, N. S. K.; Babu, K. R.; Ramakrishna, G.; Tetrahedron Lett. 2017, 58, 1127.

9. Nanke, Y.; Kobashigawa, T.; Yago, T.; Kawamoto, M.; Yamanaka, H.; Kotake, S.; BioMed Res. Int. 2016, 6824719.

10. Kalkhambkar, R. G.; Aridoss, G.; Kulkarni, G. M.; Bapset, R. M.; Kadakol, J. C.; Premkumar, N.; Jeong, Y. T.; Monatsh. Chem. 2012, 143, 1075.

11. Vats, P.; Hadjimitova, V.; Yoncheva, K.; Kathuria, A.; Sharma, A.; Chand, K.; Duraisamy, A. J.; Sharma, A. K.; Sharma, A. K.; Saso, L.; Sharma, S. K.; Med. Chem. Res. 2014, 23, 4907.

12. Rylova, G.; Dzubak, P.; Janostakova, A.; Frydrych, I.; Konecny, P.; Holub, D.; Ozdian, T.; Dolezal, D.; Soural, M.; Hlavac, J.; Hajduch, M.; Cancer Res. 2012, 72, DOI: 10.1158/1538-7445. AM2012-4748.

13. Rylova, G.; Dzubak, P.; Janostakova, A.; Frydrych, I.; Konecny, P.; Holub, D.; Ozdian, T.; Dolezal, D.; Soural, M.; Hlavac, J.; Hajduch, M.; Cancer Res. 2014, 74, DOI: 10.1158/1538-7445. AM2014-4624.

14. Tomé, A. M.; Filipe, A.; Drug Saf. 2011, 34, 465.
15. Paramaguru, G.; Solomon, R. V.; Jagadeeswari, S.; Venuvanalingam, P.; Renganathan, R.; Eur. J. Org. Chem. 2014, 2014, 753.

16. Desiraju, G. R.; Science 2014, 343, 1057.

17. Farag, A. A. M.; Roushdy, N.; Halim, S. A.; El-Gohary, N. M.; Ibrahim, M. A.; Said, S.; Spectrochim. Acta, Part A 2018, 191, 478.

18. Bellili, A.; Pan, Y.; Al Mogren, M. M.; Lau, K. C.; Hochlaf, M.; Spectrochim. Acta, Part A 2016, 164, 1.

19. Bruker-AXS; APEX2 Version 2014; Wisconsin, USA, 2014.

20. Sheldrick, G. M.; Acta Crystallogr., Sect. C: Struct. Chem. 2015, 71, 3 .

21. Farrugia, L. J.; J. Appl. Crystallogr. 2012, 45, 849.

22. Macrae, C. F.; Edgington, P. R.; McCabe, P.; Pidcock, E.; Shields, G. P.; Taylor, R.; Towler, M.; van de Streek, J.; J. Appl. Crystallogr. 2006, 39, 453.

23. Spek, A. L.; J. Appl. Crystallogr. 2003, 36, 7.

24. McKinnon, J. J.; Spackman, M. A.; Mitchell, A. S.; Acta Crystallogr., Sect. B: Struct. Sci. 2004, 60, 627.

25. Spackman, M. A.; McKinnon, J. J.; CrystEngComm 2002, 4, 378.

26. Wood, P. A.; McKinnon, J. J.; Parsons, S.; Pidcock, E.; Spackman, M. A.; CrystEngComm 2008, 10, 368.

27. Spackman, M. A.; Jayatilaka, D.; CrystEngComm 2009, 11, 19.

28. Chattopadhyay, B.; Mukherjee, A. K.; Narendra, N.; Hemantha, H. P.; Sureshbabu, V. V.; Helliwell, M.; Mukherjee, M.; Cryst. Growth Des. 2010, 10, 4476.

29. Frisch, M. J.; Trucks, G. W.; Schlegel, H. B.; Scuseria, G. E.; Robb, M. A.; Cheeseman, J. R.; Scalmani, G.; Barone, V.; Mennucci, B.; Petersson, G. A.; Nakatsuji, H.; Caricato, M.; Li, X.; Hratchian, H. P.; Izmaylov, A. F.; Bloino, J.; Zheng, G.; Sonnenberg, J. L.; Hada, M.; Ehara, M.; Toyota, K.; Fukuda, R.; Hasegawa, J.; Ishida, M.; Nakajima, T.; Honda, Y.; Kitao, O.; Nakai, H.; Vreven, T.; Montgomery Jr., J. A.; Peralta, J. E.; Ogliaro, F.; Bearpark, M.; Heyd, J. J.; Brothers, E.; Kudin, K. N.; Staroverov, V. N.; Kobayashi, R.; Normand, J.; Raghavachari, K.; Rendell, A.; Burant, J. C.; Iyengar, S. S.; Tomasi, J.; Cossi, M.; Rega, N.; Millam, J. M.; Klene, M.; Knox, J. E.; Cross, J. B.; Bakken, V.; Adamo, C.; Jaramillo, J.; Gomperts, R.; Stratmann, R. E.; Yazyev, O.; Austin, A. J.; Cammi, R.; Pomelli, C.; Ochterski, J. W.; Martin, R. L.; Morokuma, K.; Zakrzewski, V. G.; Voth, G. A.; Salvador, P.; Dannenberg, J. J.; Dapprich, S.; Daniels, A. D.; Farkas, Ö.; Foresman, J. B.; Ortiz, J. V; Cioslowski, J.; Fox, D. J.; Gaussian 09, Revision A.02; Gaussian Inc., Wallingford CT, 2009.

30. Seifert, N. A.; Steber, A. L.; Neill, J. L.; Pérez, C.; Zaleski, D. P.; Pate, B. H.; Lesarri, A.; Phys. Chem. Chem. Phys. 2013, 15, 11468.

31. Michelini, L. J.; Castro, M. R. C.; Custodio, J. M. F.; Naves, L. F. N.; Vaz, W. F.; Lobón, G. S.; Martins, F. T.; Perez, C. N.; Napolitano, H. B.; J. Mol. Struct. 2018, 1168, 309. 
32. Singh, S. K.; Joshi, P. R.; Shaw, R. A.; Hill, J. G.; Das, A.; Phys. Chem. Chem. Phys. 2018, 20, 18361.

33. Garnica, M. M.; Torres, A. E.; Ramírez-Caballero, G. E.; Balbuena, P. B.; Microporous Mesoporous Mater. 2018, 265, 241.

34. Zhao, Y.; Truhlar, D. G.; Theor. Chem. Acc. 2008, 120, 215.

35. Sert, Y.; Ucun, F.; El-Hiti, G. A.; Smith, K.; Hegazy, A. S.; J. Spectrosc. 2016, 2016, 1.

36. James, W. H.; Buchanan, E. G.; Müller, C. W.; Dean, J. C.; Kosenkov, D.; Slipchenko, L. V.; Guo, L.; Reidenbach, A. G.; Gellman, S. H.; Zwier, T. S.; J. Phys. Chem. A 2011, 115, 13783.

37. Jamroz, M. H.; Vibrational Energy Distribution Analysis VEDA 4; Warsaw, Poland, 2004.

38. Dennington, R.; Keith, T.; Millam, J.; GaussView, version 5; Semichem Inc., Shawnee Mission, Kansas, 2009.

39. Alecu, I. M.; Zheng, J.; Zhao, Y.; Truhlar, D. G.; J. Chem. Theory Comput. 2010, 6, 2872.

40. Custodio, J. M. F.; Faria, E. C. M.; Sallum, L. O.; Duarte, V. S.; Vaz, W. F.; de Aquino, G. L. B.; Carvalho Jr., P. S.; Napolitano, H. B.; J. Braz. Chem. Soc. 2017, 28, 2180.
41. Pavia, D. L.; Lampman, G. M.; Kriz, G. S.; Vyvyan, J. A.; Introduction to Spectroscopy, $5^{\text {th }}$ d.; Cengage Learning: Mason, Ohio, USA, 2015.

42. Raj, A.; Raju, K.; Varghese, H. T.; Granadeiro, C. M.; Nogueira, H. I. S.; Panicker, C. Y. Y.; J. Braz. Chem. Soc. 2009, 20, 549.

43. Panicker, C. Y.; Varghese, H. T.; John, M. A.; Harikumar, B.; Orient. J. Chem. 2008, 24, 973.

44. Mooney, E. F.; Spectrochim. Acta 1964, 20, 1021.

45. Ramaganthan, B.; Gopiraman, M.; Olasunkanmi, L. O.; Kabanda, M. M.; Yesudass, S.; Bahadur, I.; Adekunle, A. S.; Obot, I. B.; Ebenso, E. E.; RSC Adv. 2015, 5, 76675.

46. Sklenar, H.; Jäger, J.; Int. J. Quantum Chem. 1979, 16, 467.

47. Karthiga Devi, P.; Venkatachalam, K.; J. Mater. Sci.: Mater. Electron. 2016, 27, 8590.

Submitted: December 7, 2018

Published online: June 5, 2019 